Research Article

\title{
Evaluation of Pavement Performance due to Overload Single-Trip Permit Truck Traffic in Wisconsin
}

\author{
Hani H. Titi $\mathbb{D}^{1}{ }^{1}$ Nicholas J. Coley, ${ }^{1}$ and Valbon Latifi, ${ }^{1,2}$ \\ ${ }^{1}$ Department of Civil and Environmental Engineering, University of Wisconsin-Milwaukee, 3200 N. Cramer St., Milwaukee, \\ WI 53211, USA \\ ${ }^{2}$ Bloom Companies, LLC, 10501 Research Drive, Milwaukee, WI 53226, USA \\ Correspondence should be addressed to Hani H. Titi; hanititi@uwm.edu
}

Received 31 March 2018; Accepted 5 June 2018; Published 1 August 2018

Academic Editor: Ghassan Chehab

Copyright (c) 2018 Hani H. Titi et al. This is an open access article distributed under the Creative Commons Attribution License, which permits unrestricted use, distribution, and reproduction in any medium, provided the original work is properly cited.

\begin{abstract}
This study investigated the impacts of overweight (OW) permit truck traffic on flexible pavement performance in Wisconsin using field investigation and analysis utilizing the AASHTOWare Pavement ME Design software. A database of overweight single-trip permit truck records was analysed to produce a network of Wisconsin corridors heavily travelled by OW trucks. Four Wisconsin highways were selected for investigation due to high levels of OW truck traffic. The research included field work (traffic counts and visual pavement surface distress surveys) and AASHTOWare Pavement ME Design. Comprehensive analyses were conducted to evaluate pavement performance due to normal traffic loads as well as normal traffic loads plus the OW truck traffic loads. The use of mechanistic-empirical (ME) pavement analyses provided a methodology for estimating the proportion of pavement deterioration attributable to OW truck traffic. OW axle load distributions were developed and integrated with baseline truck traffic levels to develop axle load spectra and other traffic input parameters for the ME pavement analysis. The predicted total pavement deterioration levels from the AASHTOWare Pavement ME Design software were generally consistent with the levels of deterioration observed. The proportion of pavement damage and deterioration attributable to $\mathrm{OW}$ truck traffic was predicted to constitute a relatively minor proportion of total deterioration, with most distress indices showing relative increases of approximately $0.5 \%$ to $4 \%$, with a few outliers. However, due to the small proportion of OW vehicles relative to the overall traffic levels, the OW vehicles were generally predicted to cause up to ten times the per-truck damage as compared with a typical legalweight truck, depending on the distress mode and the test site.
\end{abstract}

\section{Introduction}

With increasing numbers of oversize-overweight (OSOW) vehicle permits issued across the United States as the economy continues to grow, increased scrutiny is being applied to the infrastructure impacts of OSOW vehicles and to the assessment of vehicle size and weight programs from a policy perspective. Of particular concern to pavement professionals are overweight $(\mathrm{OW})$ vehicles, which frequently use additional axles and higher-than-normal axle loadings during the transport of heavy loads. With the implementation of AASHTOWare Pavement ME Design techniques within the past decade, a new avenue has opened for researching the effects of variations in traffic and axle load spectra (ALS) scenarios on pavement performance. Because pavement deterioration predictions in the AASHTOWare Pavement ME Design models are dependent on detailed traffic and ALS data, determining site-specific ALS variations-especially with regard to the heaviest vehicles-is a crucial step in performing accurate analyses. The objective of this research is to characterize the relative contribution to pavement damage and deterioration induced by single-trip OW permit truck traffic on selected asphalt pavements test sections in Wisconsin. The results of a comprehensive OSOW single-trip permit mapping effort were used to identify state highway segments with high levels of OW truck traffic. Pavement damage was investigated through field studies of the selected highways, generation of site-specific OW permit vehicle ALS using 
a comprehensive database of single-trip permits issued in Wisconsin, and comparative pavement performance analyses using AASHTOWare Pavement ME Design software.

\section{Background}

2.1. Oversize-Overweight Permit Programs. In the United States, individual states have the authority to issue permits to oversize and overweight (OSOW) vehicles exceeding national and state size and weight limits [1]. Typically, states' size and weight limits are based on federal limits adopted for the interstate highway system. The most common weight limits include $88.96 \mathrm{kN}$ (20 kips) for a single axle, $151.24 \mathrm{kN}$ (34 kips) for a tandem axle, and $355.86 \mathrm{kN}$ (80 kips) gross vehicle weight (GVW); the typical dimensional limits include maximum width of $2.59 \mathrm{~m}(8.5 \mathrm{ft})$, maximum height of 4.11 to $4.27 \mathrm{~m}$ (13.5 to $14 \mathrm{ft}$ ), and variable maximum length limits, depending on the vehicle and axle configuration. The precise size and weight limits depend heavily on the regulations adopted in each individual state, and numerous exemptions and variations in weight limit formulas often exist. For example, in Wisconsin the maximum weight of a group of two or more axles (tandem or greater) is determined based on the spacing between the first and last individual axle within the group. Furthermore, exceptions exist such as higher axle weight limits for vehicles carrying agricultural products or implements, forestry products, or milk products [2]. Motor vehicle operators wishing to operate vehicles exceeding states' size and weight limits must apply for OSOW permits from each individual state, in accordance with each state's regulations. Although many overweight permit vehicles utilize six or more axles or occasionally more than 4 tires per axle to distribute the load across a greater pavement area, some permit vehicles may also include axle loadings exceeding statutory limits. Recent years have seen dramatic increases in the number of OSOW permits obtained in various states, including in the number of superheavy vehicle permits, that is, vehicles with a GVW of at least 1,201 kN (270 kips) [3].

In Wisconsin, $74 \%$ of total freight tonnage is carried by truck, a crucial transportation mode in a state that produces or processes over $\$ 300$ billion USD in goods annually [4]. Over the last 25 years, average loads transported on ships and trains have become heavier while truck loads have stayed constant-largely due to size and weight limits-leading to an increase in the pressure to understand and evaluate OSOW permit practices.

The Wisconsin Department of Transportation (WisDOT) issues both single-trip and multitrip permits for OSOW vehicles [5]. Single-trip permits are granted for a specific vehicle and route. Permit routes for vehicles with GVW of less than 270 kips are automatically analysed by WisDOT's enterprise GIS system, which includes a database of segment restrictions such as bridge ratings, spring thaw limitations, and temporal restrictions due to traffic regulations or special events [6]. Superheavy vehicle permits for vehicles heavier than $1,201 \mathrm{kN}$ (270 kips) are analysed manually by WisDOT's bridge and pavement engineering divisions before approval. Multitrip permits allow the carrier to operate vehicles up to $756.2 \mathrm{kN}$ (170 kips) GVW without restriction within the permit's timeframe (three to twelve months), but the precise vehicle weights, dimensions, and route information are not recorded by WisDOT; therefore, single-trip permits constitute the focus of this paper.

\subsection{Pavement Analysis Related to Overweight Vehicles.} Previous studies of the effect of heavy truck loads on pavement damage and performance have been conducted using various techniques, including field investigations and measurements as well as mechanistic and theoretical analyses using tools such as finite element methods. Several of these studies were conducted on specific pavements based on observations of pavement damage or in relation to specific superheavy load moves [3, 7-14].

Premature fatigue cracking and rutting have been described on routes experiencing large numbers of overweight vehicles, for example, in northern Wisconsin on federal highways with large numbers of overweight logging trucks [10]. Acute pavement damage from permit vehicle loads has also been reported, including seal coat stripping in Texas [3] and severe rutting and cracking in Louisiana [15]. Superheavy loads above $4,448.2 \mathrm{kN}$ (1,000 kips) have been reported, including a $4,470.5 \mathrm{kN}$ (1,005 kips) turbine skid in Ohio and a $8798.6 \mathrm{kN}$ (1,978 kips) hydroreactor in Louisiana.

\section{Permit Route Mapping and Site Selection}

In order to assess the relative impact of OW vehicles on pavement performance, a multifaceted approach was chosen consisting of OW permit data consolidation, selection of highway sites for detailed study, pavement condition surveys in the field, and AASHTOWare Pavement ME Design pavement performance simulations under multiple traffic input scenarios developed using site-specific OW permit records. Coley et al. [16] constructed a comprehensive database of OSOW single-trip permit records in Wisconsin and developed processing techniques, which mapped the permit routes to the highway network in Wisconsin. Using the available text-based permit records, each permit's route was matched to the specific highway segments and intersections traversed by that permit vehicle through the development of custom text-parsing and network analysis algorithms implemented within a geographic information system (GIS) framework. The OSOW permits database encompasses all single-trip permits issued in Wisconsin between May 2007 and March 2017, including axle records for OW permits. The route matching algorithms succeeded in mapping $98.4 \%$ of all single-trip permits. Crucially, the database allowed for the generation of site-specific axle load spectra (ALS) frequency counts for any highway segment; this provided the data necessary to adjust the ALS to incorporate OW vehicles into the traffic inputs for AASHTOWare Pavement ME Design analysis, as discussed later in this paper. Frequency maps of OW permit traffic were generated, as well as maps of $\mathrm{cu}-$ mulative equivalent single axle loads (ESALs) due to OW permit vehicles, as demonstrated in Figure 1. 

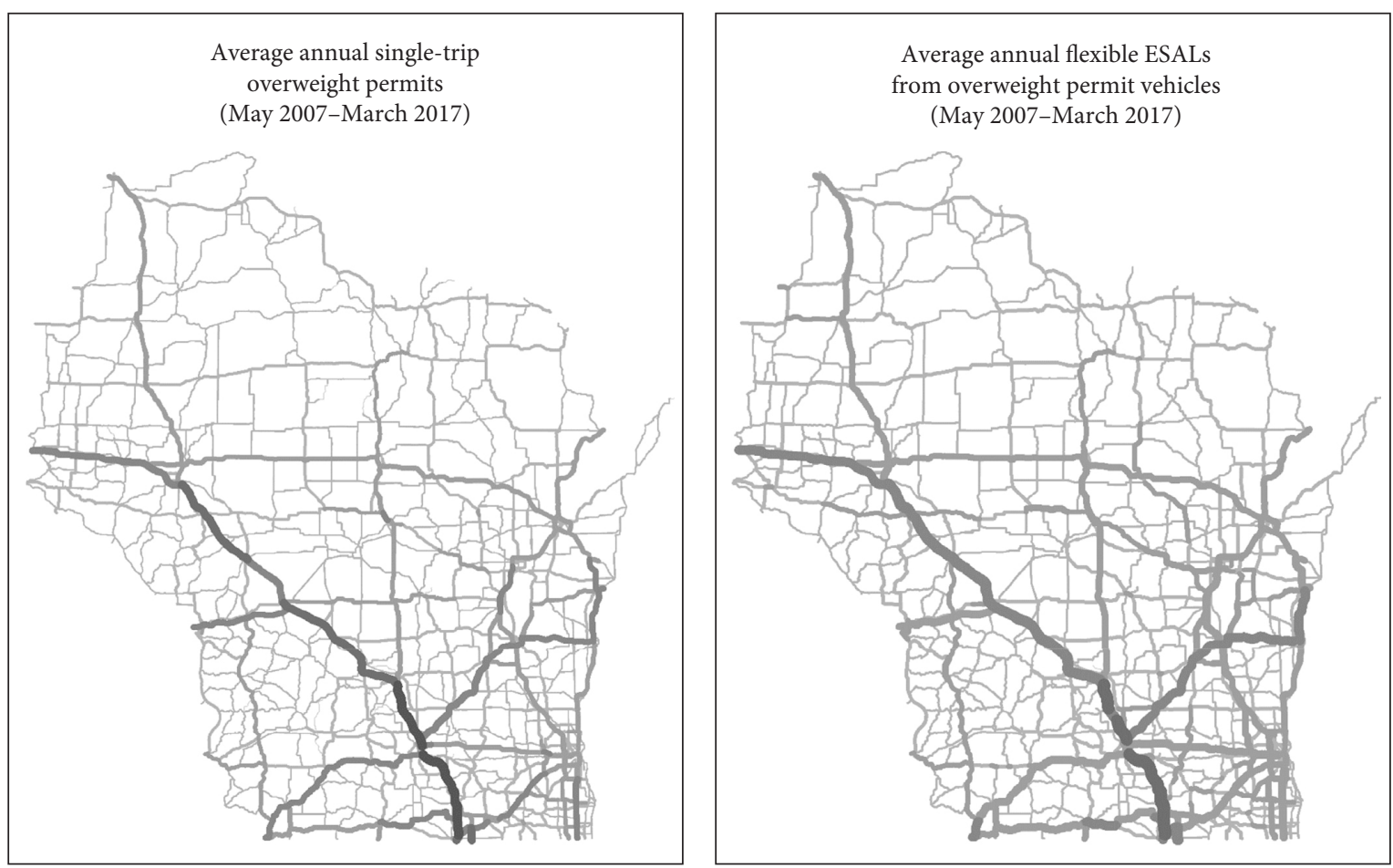

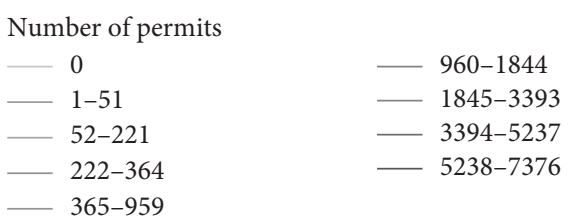

(a)

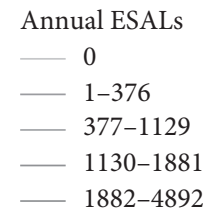

$1882-4892$

FIGURE 1: Statewide OW permit route analysis maps. (a) Map of OW permit frequency and (b) map of OW permit ESALs.

In order to assess and better understand the expected pavement impacts of typical OW vehicles using tradition ESAL-based pavement analysis methods, a histogram of ESALs-per-truck was created showing the distribution of ESALs over the entire OW permit database (Figure 2). This analysis demonstrates that the most common ESAL values for OW trucks lie between roughly 1 and 8 ESALs (average is 6.17), with a relatively small number of trucks with ESALs greater than 15 (maximum is 319.6).

In addition to the map visualizations and analyses conducted on a statewide scale, the results of the prior permit mapping work allowed for the precise identification of permit vehicles travelling on any given highway segment in the state. Based on the calculation of the highways in the state experiencing the most OW permit traffic (Figure 3), four Wisconsin State Trunk Highway (STH) segments were selected for investigation and analysis as presented in this paper: STH 140 near Clinton, STH 11 near Delavan, STH 23 near Plymouth, and STH 26 near Waupun (Table 1). The criteria for selecting these highways included higher-thannormal OW vehicle traffic, ease of site accessibility, ability to provide traffic control and safety for the researchers while performing pavement surveys, and suitably long timeframes since the last reconstruction to allow for comparisons of

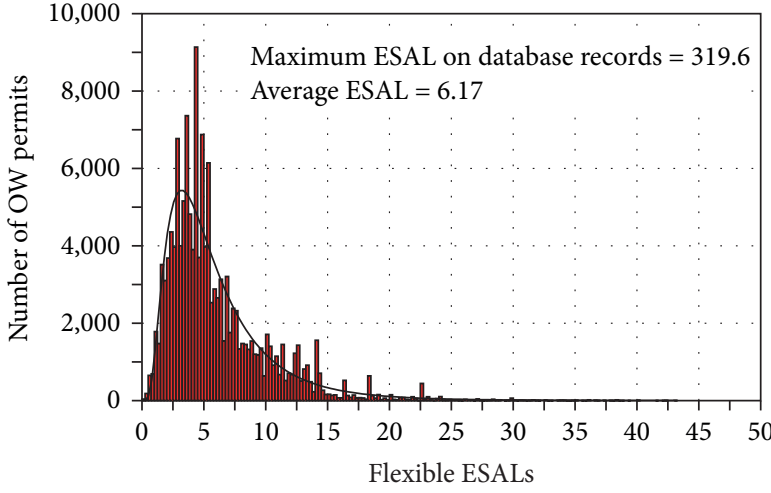

FIGURE 2: Distribution of flexible ESALs by truck for single-trip OW permit vehicles in Wisconsin.

observed versus predicted pavement distresses. All four sites were two-lane highways in relatively rural areas constructed primarily of asphalt concrete flexible pavements, as this represents the vast majority of the highway system in Wisconsin, excluding freeways and urban segments.

With $2.15,2.68$, and $1.66 \mathrm{OW}$ permits per day respectively, the specific sites selected along STH 11, STH 23, and STH 26 experienced higher-than-normal volumes of 


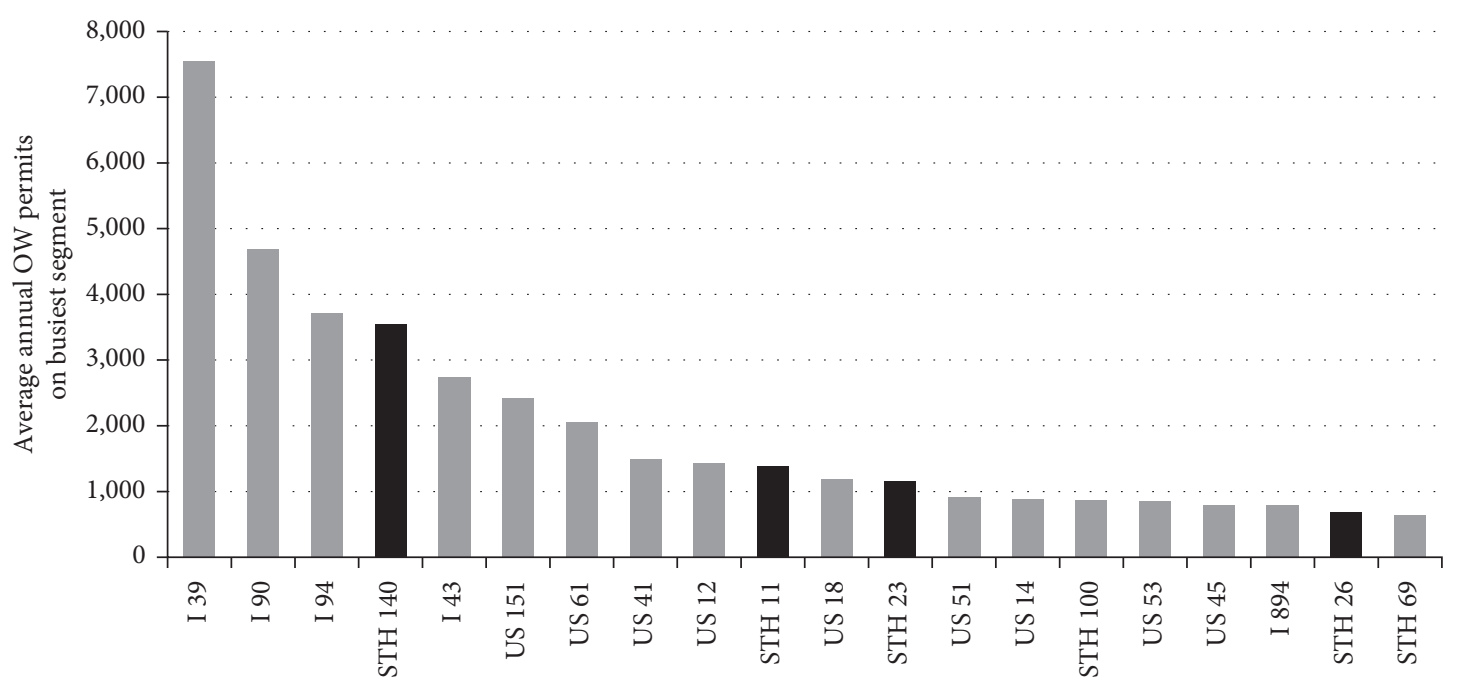

FIGURE 3: Most heavily travelled highways by single-trip OW permit trucks, with selected test highways highlighted.

TABLE 1: Truck and OW permit traffic levels at investigated test sites.

\begin{tabular}{|c|c|c|c|c|}
\hline & STH 140 & STH 11 & STH 23 & STH 26 \\
\hline Total OW permits (six-year dataset) & 21,201 & 4,778 & 5,951 & 3,684 \\
\hline Daily OW permits & 9.54 & 2.15 & 2.68 & 1.66 \\
\hline AADT & 2,600 & 3,102 & 7,443 & 6,952 \\
\hline Estimated percent truck & $20 \%$ & $11.0 \%$ & $18.1 \%$ & $31.1 \%$ \\
\hline Percent OW trucks versus baseline trucks & $1.8 \%$ & $0.58 \%$ & $0.25 \%$ & $0.077 \%$ \\
\hline
\end{tabular}

OW vehicle traffic, in a range consistent with other hightraffic two-lane highways. STH 140 experienced permit vehicle traffic levels of 9.54 permits per day, which is significantly higher than on any other state highway in Wisconsin and is comparable to permit traffic on interstate highways (Figure 2). STH 140 is a $19.31 \mathrm{~km}$ (12 mile) long north-south highway stretching from IL-76 south of the Illinois border north to I-43, and it parallels I-39/90 which crosses the state border seven miles to the west; I-39/90 is a major interstate corridor and the most heavily travelled highway for OW vehicles in the state. From discussions with WisDOT OSOW permit issuance staff, it was ascertained that the anomalously high level of OW traffic on STH 140 stems from carriers avoiding toll plazas south of the state border in Illinois where I-39/90 is a toll road. Permit data analysis showed that STH 140 carries $60 \%$ of OW permit traffic crossing the state border along the I-39/90 corridor.

\section{Site Investigation and Data Collection}

Each selected segment was visited by the researchers in order to conduct site assessments, visual pavement surveys, and 6-hour traffic counts along a representative $45.7 \mathrm{~m}$ (150 ft.) section of roadway. The surveys were conducted in accordance with ASTM D6433 [17] "Standard Practice for Roads and Parking Lots Pavement Condition Index Surveys," in order to calculate the Pavement Condition Index (PCI) using MicroPAVER software. This assessment included the precise notation of all fatigue (alligator) cracking areas, longitudinal and transverse cracking, ravelling, potholes, polished aggregate, edge cracking, and rutting measurements.

Traffic counts were conducted at each location over 6hour weekday periods to provide supplemental traffic data to improve traffic estimates derived from historical traffic counts and WisDOT-developed estimates of vehicle class distributions. Traffic counts at each site included the visual identification of likely OSOW vehicles based on oversize markings and significant numbers of axles to confirm the presence of OSOW traffic at each test site (Figure 4). Percent truck values were obtained from nearby historical count sites for each test site. Additional site data were obtained from WisDOT including pavement sections, rehabilitation histories, and limited material properties at the selected sites. Supplementary information on typical subgrade soil moduli was obtained from existing research results [18]. The originally constructed pavement typical sections and rehabilitation measures for the highway segments analysed are summarized in Table 2. The typical sections as well as estimates of material properties and the traffic parameters were used as inputs for the AASHTOWare Pavement ME Design pavement performance analyses and are discussed later in this paper.

The results from the pavement surface distress surveys are presented in Table 3 and show various levels of pavement distresses at the test sites, with PCI ratings of "Serious" on STH 140 and STH 26, "Very Poor" and "Poor" on STH 11, and "Fair" on STH 23. Diagrams of the visually observed distresses are presented in Figure 5. The test section of STH 140 displayed very significant deterioration of the pavement 


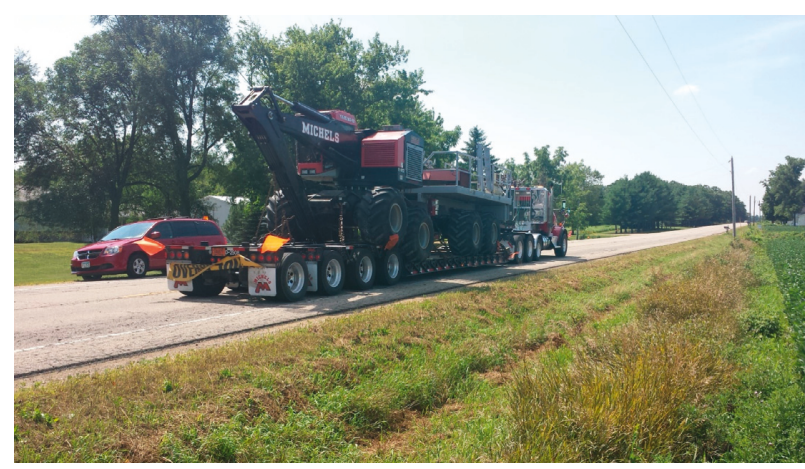

(a)

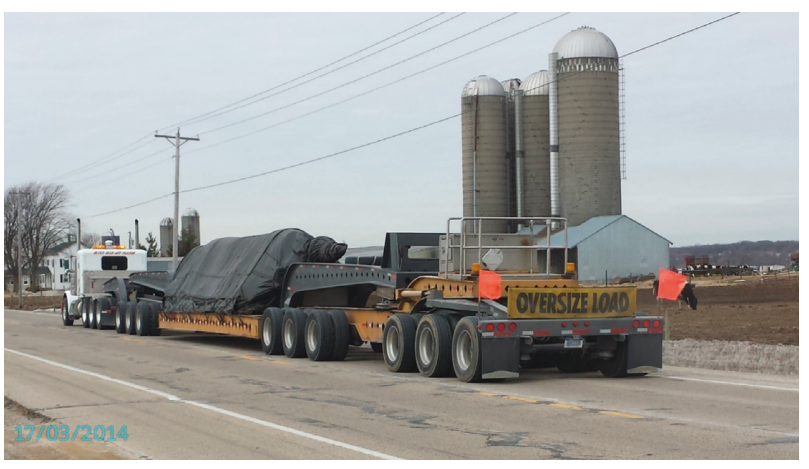

(b)

FIgURE 4: OSOW vehicles observed during field traffic counts.

TABle 2: Pavement structures at investigated highway test sites.

\begin{tabular}{|c|c|c|c|c|}
\hline \multirow{2}{*}{ Highway test site } & \multicolumn{2}{|c|}{ HMA surface } & \multirow{2}{*}{ Base (crushed aggregate) } & \multirow{2}{*}{$\begin{array}{l}\text { Most recent construction/ } \\
\text { rehabilitation year }\end{array}$} \\
\hline & Most recent overlay & Existing layer after milling & & \\
\hline STH 140 & $51 \mathrm{~mm}(2$ in $)$ & $102 \mathrm{~mm}(4 \mathrm{in})$ & $203 \mathrm{~mm}$ (8 in) & 1996 \\
\hline STH 11 & $114 \mathrm{~mm}(4.5 \mathrm{in})$ & $165 \mathrm{~mm}(6.5 \mathrm{in}) \mathrm{PCC}$ & $152 \mathrm{~mm}(6 \mathrm{in})$ & 1987 \\
\hline STH 23 & $64 \mathrm{~mm}(2.5 \mathrm{in})$ & $102 \mathrm{~mm}(4 \mathrm{in})$ & $330 \mathrm{~mm}$ (13 in) & 2004 \\
\hline STH 26 & $76 \mathrm{~mm}(3 \mathrm{in})$ & $83 \mathrm{~mm}(3.25 \mathrm{in})$ & $203 \mathrm{~mm}$ (8 in) & 1997 \\
\hline
\end{tabular}

TABLE 3: Summary of pavement distress survey results.

\begin{tabular}{|c|c|c|c|c|c|}
\hline Pavement surface distress & & STH 140 & STH 11 & STH 23 & STH 26 \\
\hline \multirow[t]{2}{*}{ Fatigue cracking ( $\%$ area $)$} & & 12.7 & 7.6 & 4.1 & 10.2 \\
\hline & High severity & 52.7 & 10.7 & 3 & 47.5 \\
\hline \multirow[t]{2}{*}{ Longitudinal + transverse cracking length $(\mathrm{m})$} & Med. severity & 120.7 & 102.1 & 33.5 & 124.4 \\
\hline & Low severity & 25 & 31.1 & 43.6 & 28.3 \\
\hline \multirow{2}{*}{ Max rutting $(\mathrm{mm})$} & Outer wheel paths & 25 & 21 & 10 & 32 \\
\hline & Inner wheel paths & 8 & 22 & 13 & 14 \\
\hline \multirow{2}{*}{ Average rutting $(\mathrm{mm})$} & Outer wheel paths & 13 & 16 & 7 & 20 \\
\hline & Inner wheel paths & 1.5 & 17 & 11 & 11 \\
\hline \multirow{2}{*}{ PCI index \& rating } & Direction 1 & 13 (serious) & 40 (very poor) & 63 (fair) & 14 (serious) \\
\hline & Direction 2 & 17 (serious) & 52 (poor) & 66 (fair) & 15 (serious) \\
\hline
\end{tabular}

within the driving lanes as well as within the shoulder, with PCI values of 13 and 17. STH 11 presented significant yet less severe deterioration with PCI values of 40 and 52. STH 23 had the least distressed pavement surface of the investigated sites, with calculated PCI values of 63 and 66, likely due in part to its relatively recent reconstruction in 2004. The pavement surface condition at the investigated segment of STH 26 showed the most deterioration among the investigated highways, including very significant cracking, ravelling, and rutting, with PCI values calculated to be 14 and 15 .

\section{Mechanistic-Empirical Analysis Using Meshed Axle Load Spectra}

Axle load spectra (ALS), vehicle class distributions (VCD), monthly adjustment factors, and axles-per-truck values are crucial traffic input parameters for AASHTOWare Pavement ME Design software. WisDOT developed typical ALS and for normal (baseline) traffic in Wisconsin using historical weigh-in-motion (WIM) data. The ALS developed by WisDOT is designed to function as a level 2 statewide input for pavement ME software, which can be used as regionally developed default traffic inputs for pavement analysis. WisDOT [19] also developed VCD, monthly adjustment factors, and axles-per-truck values specific to highway functional classifications, which were obtained for the test sites' classifications. Similarly, regionally adjusted calibration factors for use in the mechanistic-empirical software calculations were obtained from WisDOT, which modified some of the global calibration factors provided with AASHTOWare Pavement ME Design version 2.3.1.

Using these level 2 "baseline" traffic and axle distribution values from WisDOT, site-specific AADT and percent-truck values, and site-specific pavement profiles, baseline project files were created and run in AASHTOWare Pavement ME Design for each of the four test sites over 20-year analysis 


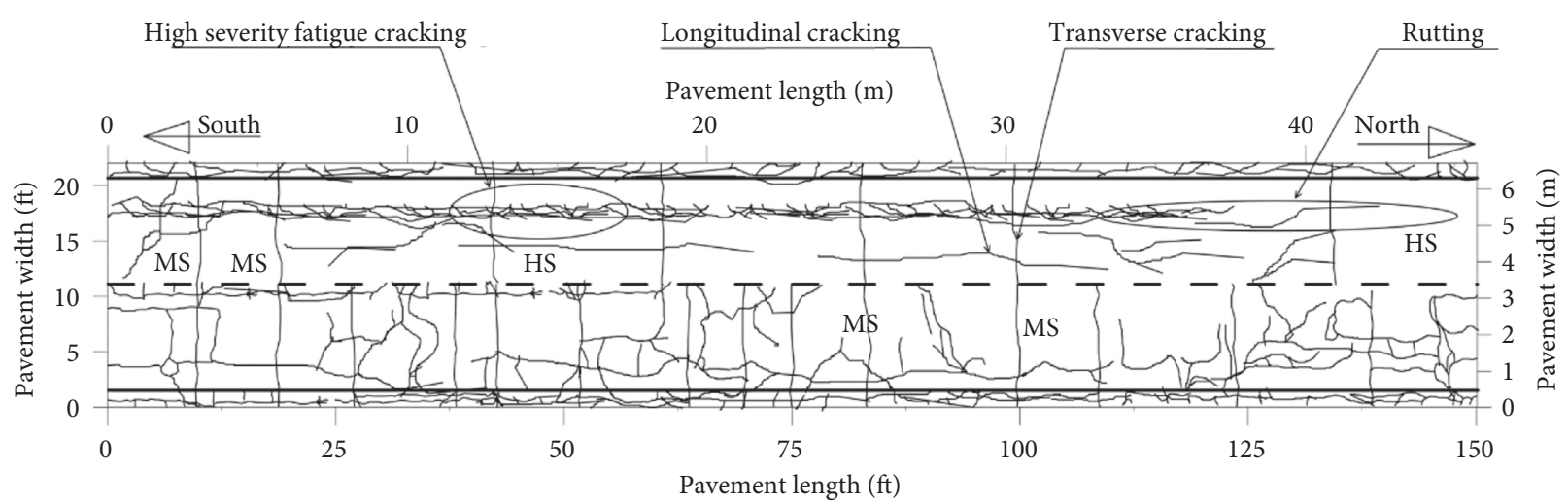

(a)

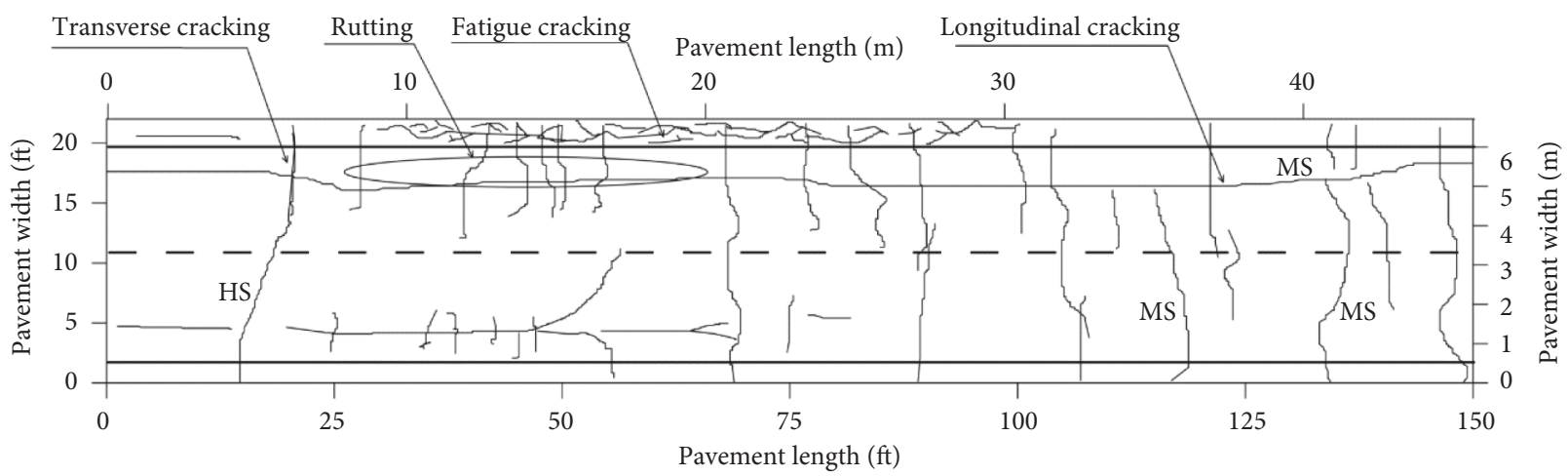

(b)

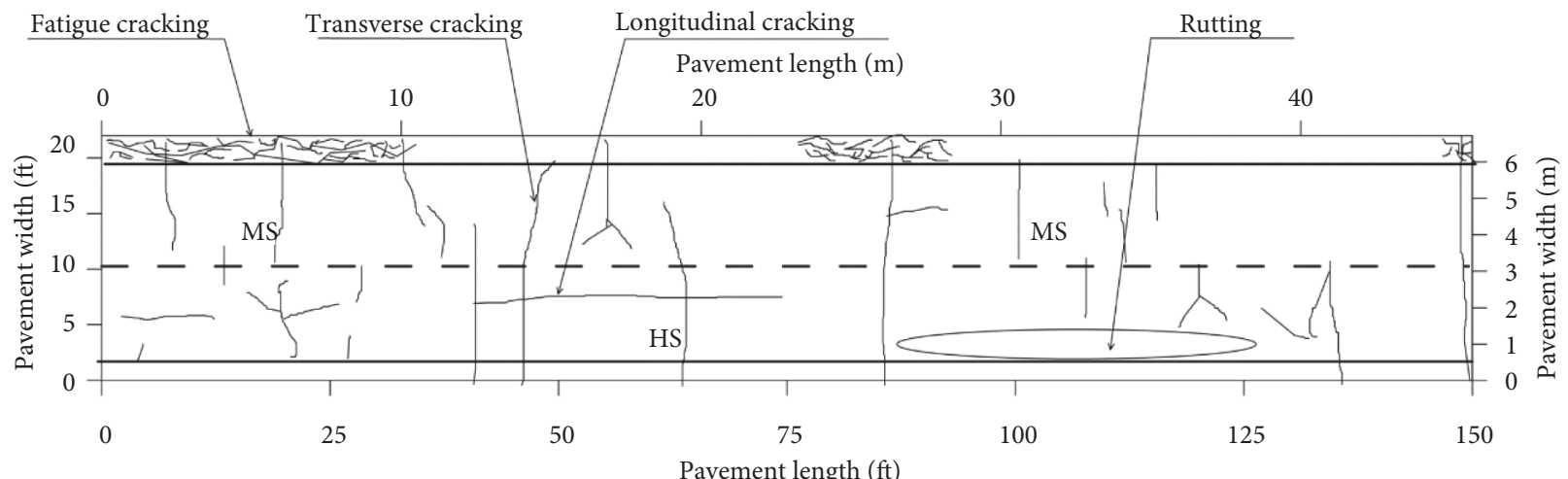

(c)

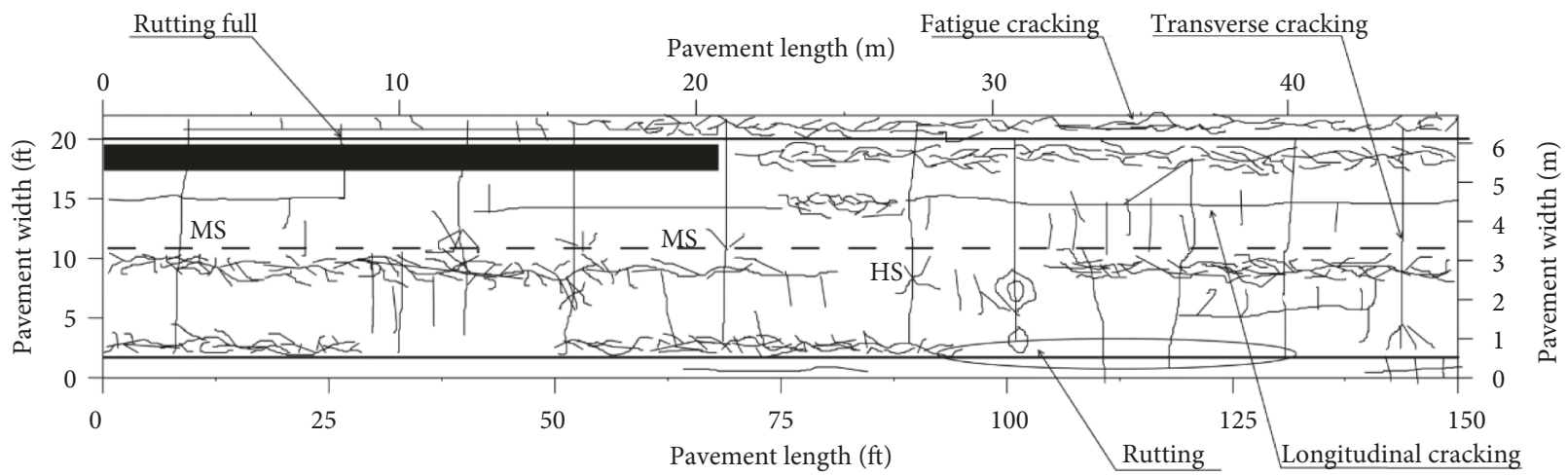

(d)

FIGURE 5: Pavement surface distress observed on investigated pavements. (a) Map of observed distress on STH 140, (b) map of observed distress on STH 11, (c) map of observed distress on STH 23, and (d) map of observed distress on STH 26. HS = high severity; MS = medium severity. 
periods. The results of these baseline analyses provided a reference point as predictions of pavement performance without the site-specific OW vehicles.

Using the OW permit records and corresponding axle records from the OSOW permits database and route mapping results, queries were written to extract OW vehicle and axle frequencies (broken down by axle weight) for each test site. Because the software only accepts inputs in terms of ALS, VCD, axles-per-truck, and monthly distribution factors, it was necessary to develop a methodology to incorporate the changes in these traffic inputs caused by overlaying OW permit traffic on top of baseline traffic. This was accomplished by disaggregating the baseline traffic inputs into simulated counts of daily vehicles and axles, broken down by vehicle class, axle type, and axle load. The daily axle load frequency counts from the site-specific OW permits were added to these axle counts derived from the baseline traffic values, which yielded average daily axle load frequency counts, incorporating baseline traffic vehicles, and OW permit vehicles. ALS were then recalculated by normalizing the frequency counts to create the meshed ALS. The VCD, monthly distribution factors, axles-per-truck, and AADT data were similarly meshed by expanding the baseline traffic distributions data into daily frequency counts, adding in the corresponding frequency counts from the $\mathrm{OW}$ vehicles, and then recalculating the distributions to create meshed traffic inputs for use in the ME analyses. This procedure created two AASHTOWare Pavement ME Design analyses for each test site with traffic distributions as the experimental variables and all other inputs-climate, pavement structure, general traffic characteristics, and calibration values-held constant. A comparison of the AASHTOWare Pavement ME Design results from the meshed traffic inputs versus baseline traffic inputs provides insight into the additional contributions to pavement damage caused by introducing OW permit vehicles into an existing baseline traffic scenario.

\section{AASHTOWare Pavement ME Design Software Analysis Results}

Figure 6 presents the ALS frequency for tandem axles at the STH 140 site for baseline trucks, OW trucks, and the meshed truck traffic, including both baseline and OW trucks. Similar ALS were developed for each highway test site and axle type. The ALS for the OW single-trip permit vehicles show higher overall axle weights than the WisDOT baseline ALS. For example, the OW permit ALS for STH 140 show that the tandem axle weight distribution is centered on $177.93 \mathrm{kN}$ (40 kips), higher than the typical baseline tandem axle weights of $88.96-151.27 \mathrm{kN}$ (20-34 kips).

The results of the $\mathrm{ME}$ analyses performed using the AASHTOWare Pavement ME Design software showed varying levels of additional pavement deterioration caused by OW vehicles, depending on the proportion of OW vehicles compared with legal-weight vehicles, and the material and pavement structures on the test sections (Table 4). The failure criteria used to evaluate pavement performance were chosen from the standard threshold values for pavement distresses and ride quality adopted by WisDOT. At STH 140, which experienced both the highest absolute number and relative number of OW vehicles (9.54 permits/day and $1.8 \%$ of total truck traffic, resp.), the OW vehicles caused increases in pavement rutting of $6.5 \%$ and increases in bottom-up fatigue cracking of $18.5 \%$; this translates into per-truck damage levels caused by OW vehicles of roughly $360 \%$ for rutting and $1,030 \%$ for bottom-up fatigue cracking (Figure 8). These results agree with an analysis of typical pertruck ESALs for OW vehicles (Figure 2).

Furthermore, the results of the ME analyses are generally in good agreement with the visual distress survey results. For example, at STH 140, the observed quantity of fatigue cracking was $12.7 \%$, which agrees very well with the predicted levels of bottom-up fatigue cracking of $13.0 \%$ and $15.4 \%$ from the ME results, with baseline traffic and baseline plus permit traffic, respectively (Figure 7).

Because the objective of this research was to address the damage caused by OW trucks-with consideration to their overall fraction of total truck traffic- an analysis was conducted of the relative increase in predicted pavement deterioration due to the addition of OW trucks, as presented in Figure 8. At each investigated highway segment, the predicted percentage increases in pavement damage are significantly greater than the relative share of OW vehicles within the total truck traffic volumes. As expected, OW vehicles are predicted to cause significantly more damage on a per-truck basis than the typical baseline truck at all investigated sites, with the most significant predicted damage increases being AC bottom-up fatigue cracking and topdown fatigue cracking, followed by rutting, with relatively small increases predicted in IRI values (which are also a function of a control variable, thermal cracking, which is unaffected by traffic loading).

\section{Conclusions}

The results of the ME analyses performed using AASHTOWare Pavement ME Design demonstrated that OW vehicles are likely to have a significantly greater relative contribution to pavement deterioration than typical legal-weight trucks in Wisconsin. For example, while OW trucks are only $1.8 \%$ of truck traffic on STH 140, they are predicted to cause $18.5 \%$ of bottom-up fatigue cracking; that is, a typical OW truck is predicted to contribute over $1000 \%$ of the bottom-up fatigue cracking caused by a typical legal-weight truck. While the absolute impacts of OW vehicles on pavement performance were predicted to be minor for the highways experiencing lower OW permit traffic volumes, the relative impact of $\mathrm{OW}$ vehicles on pavement performance was universally higher than that of typical legal-weight vehicles.

For highways such as STH 140, which experience relatively low levels of truck traffic yet also receive high levels of OSOW traffic, these analyses demonstrate the importance of accurately quantifying the specific nature of the OW vehicle traffic on those roadways. By using OSOW permit history data to develop traffic inputs for ME analyses-including ALS - the marginal contributions of OW vehicles to the pavement performance can be better understood. In the case 


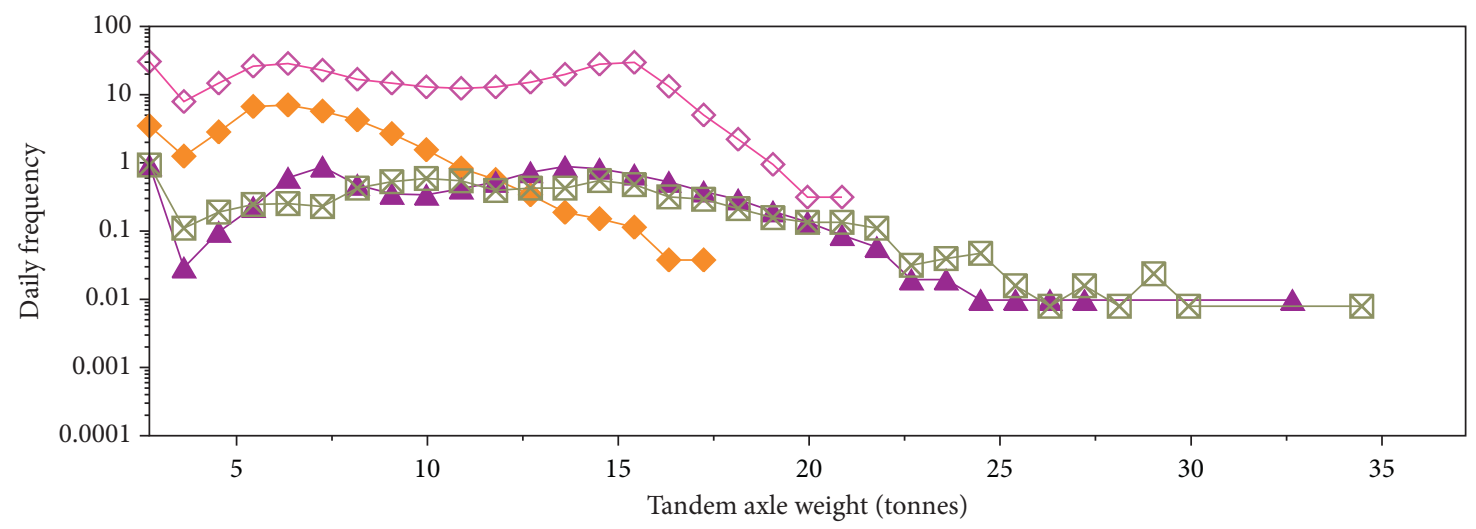

FHWA class

$\longrightarrow>8$

$\diamond \diamond \diamond 9$
$\Delta \Delta \mathbf{\Delta} 10$

\ $\bigotimes 13$

(a)

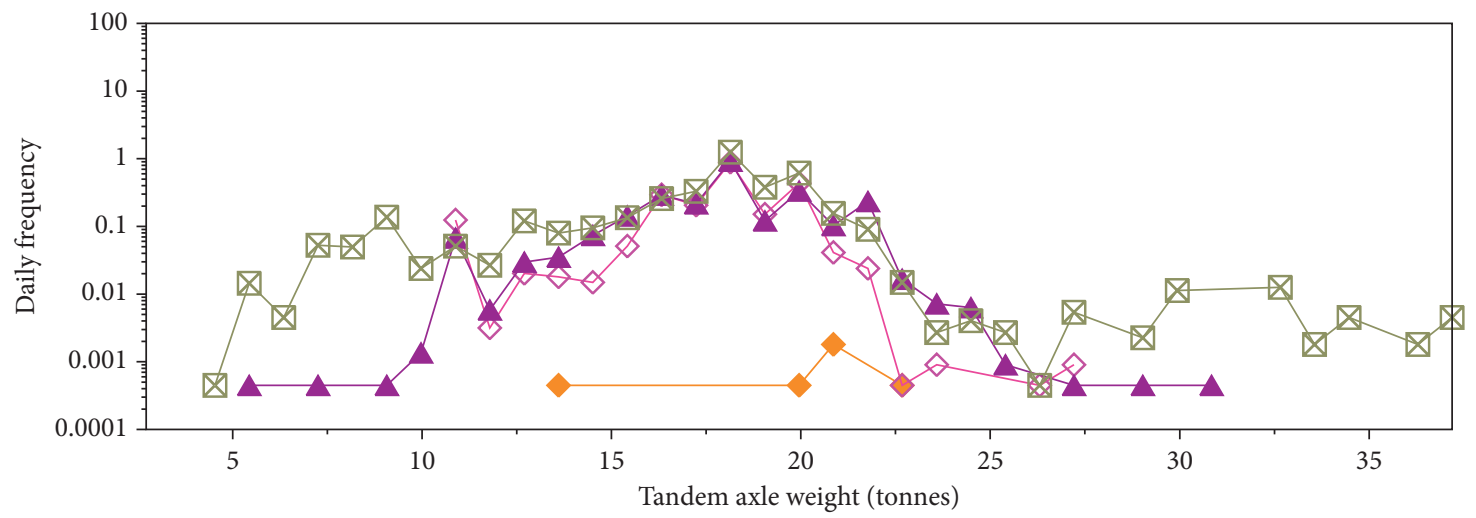

FHWA class

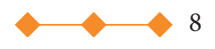

$\triangle \longrightarrow \mathbf{\Delta} 10$

$\diamond \diamond \diamond 9$

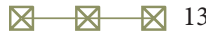

(b)

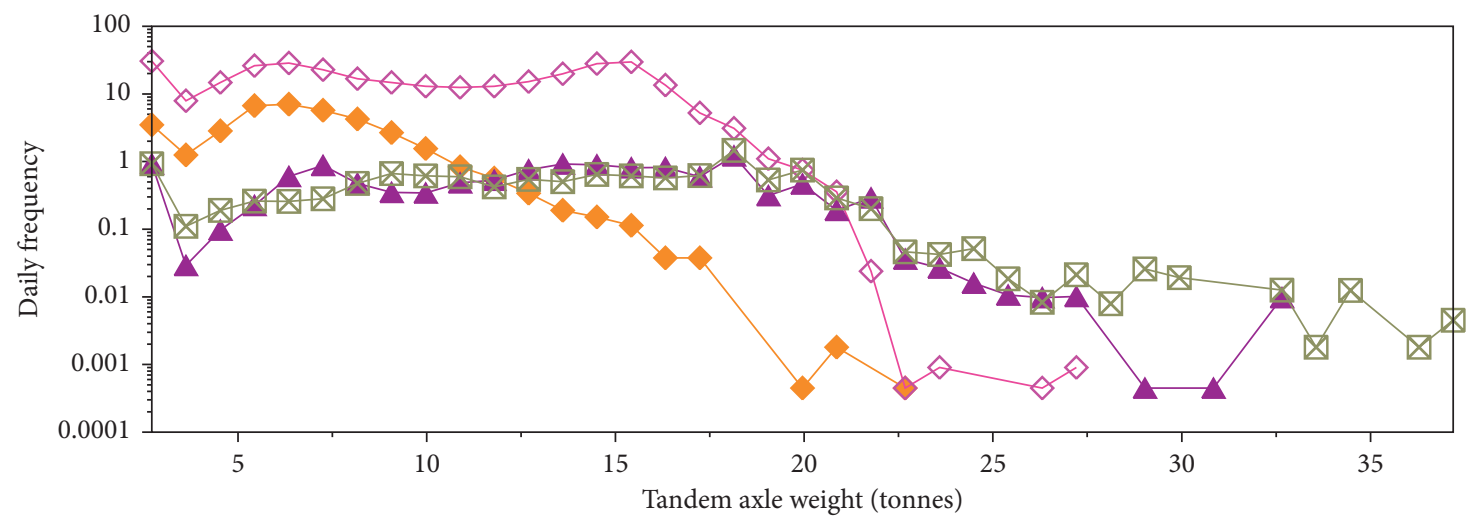

FHWA class
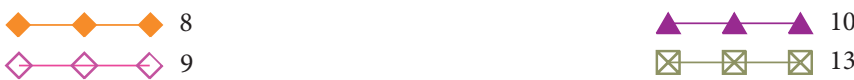

(c)

Figure 6: ALS for tandem axles developed for ME analysis of pavement on STH 140. (a) Tandem ALS frequency on STH 140 for baseline truck traffic, (b) tandem ALS frequency on STH 140 for OW permit vehicles, and (c) tandem ALS frequency on STH 140 for meshed traffic (baseline and OW trucks). Note: vehicles from classes 7, 11, and 12 are excluded due to very low frequencies of tandem axles. 
TABLE 4: ME analysis results at investigated test sites.

\begin{tabular}{|c|c|c|c|c|c|c|c|c|c|}
\hline \multirow{2}{*}{\multicolumn{2}{|c|}{$\begin{array}{l}\text { ME results } \\
\text { (at } 85 \% \text { reliability) }\end{array}$}} & \multicolumn{2}{|c|}{ STH 140} & \multicolumn{2}{|c|}{ STH 11} & \multicolumn{2}{|c|}{ STH 23} & \multicolumn{2}{|c|}{ STH 26} \\
\hline & & $\begin{array}{c}\text { Baseline } \\
\text { traffic }\end{array}$ & $\begin{array}{l}\text { Baseline } \\
+ \text { permit } \\
\text { traffic }\end{array}$ & $\begin{array}{c}\text { Baseline } \\
\text { traffic }\end{array}$ & $\begin{array}{l}\text { Baseline } \\
+ \text { permit } \\
\text { traffic }\end{array}$ & $\begin{array}{c}\text { Baseline } \\
\text { traffic }\end{array}$ & $\begin{array}{l}\text { Baseline } \\
+ \text { permit } \\
\text { traffic }\end{array}$ & $\begin{array}{c}\text { Baseline } \\
\text { traffic }\end{array}$ & $\begin{array}{l}\text { Baseline } \\
+ \text { permit } \\
\text { traffic }\end{array}$ \\
\hline \multirow{3}{*}{$\begin{array}{l}\text { Terminal IR } \\
(\mathrm{m} / \mathrm{km}) \\
\text { Rutting } \\
\text { depth } \\
(\mathrm{mm})\end{array}$} & & 1.941 & 1.952 & 1.849 & 1.852 & 1.888 & 1.890 & 1.964 & 1.964 \\
\hline & All layers & 12.3 & 13.1 & 11.4 & 11.6 & 9.09 & 9.19 & 11.2 & 11.23 \\
\hline & HMA only & 2.77 & 2.90 & 2.67 & 2.69 & 4.83 & 4.85 & 5.94 & 5.94 \\
\hline \multirow{2}{*}{$\begin{array}{l}\text { AC fatigue } \\
\text { cracking }\end{array}$} & Bottom-up (\%) & $13.0 \%$ & $15.4 \%$ & $16.39 \%$ & $16.68 \%$ & $8.72 \%$ & $9.14 \%$ & $20.56 \%$ & $20.58 \%$ \\
\hline & $\begin{array}{l}\text { Top-down } \\
(\mathrm{m} / \mathrm{km})\end{array}$ & 262.4 & 297.1 & 435.8 & 450.6 & 310.3 & 317.6 & 661.6 & 665.9 \\
\hline
\end{tabular}

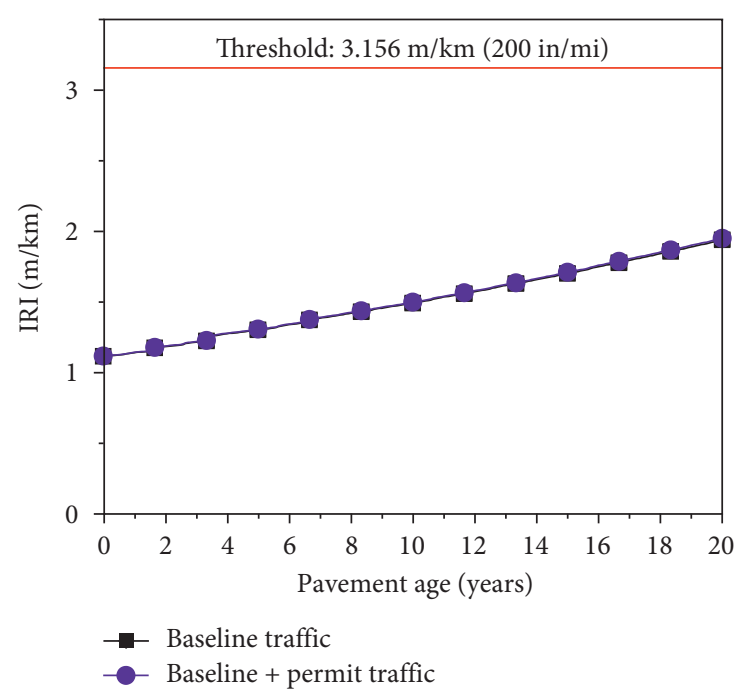

(a)

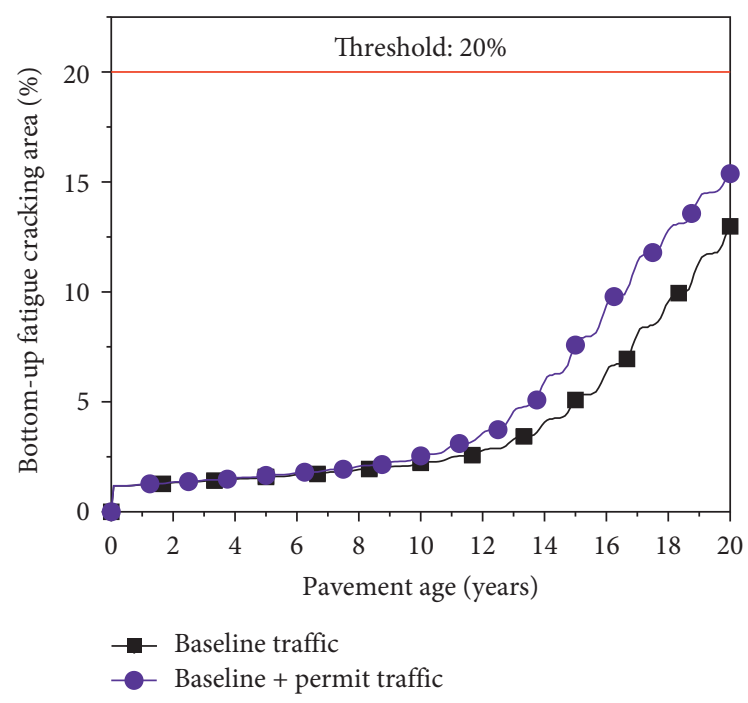

(c)

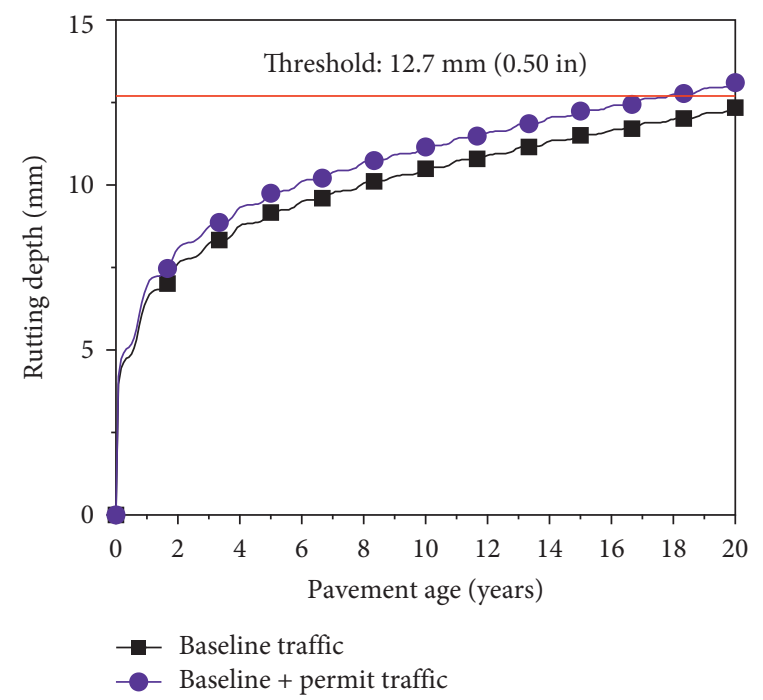

(b)

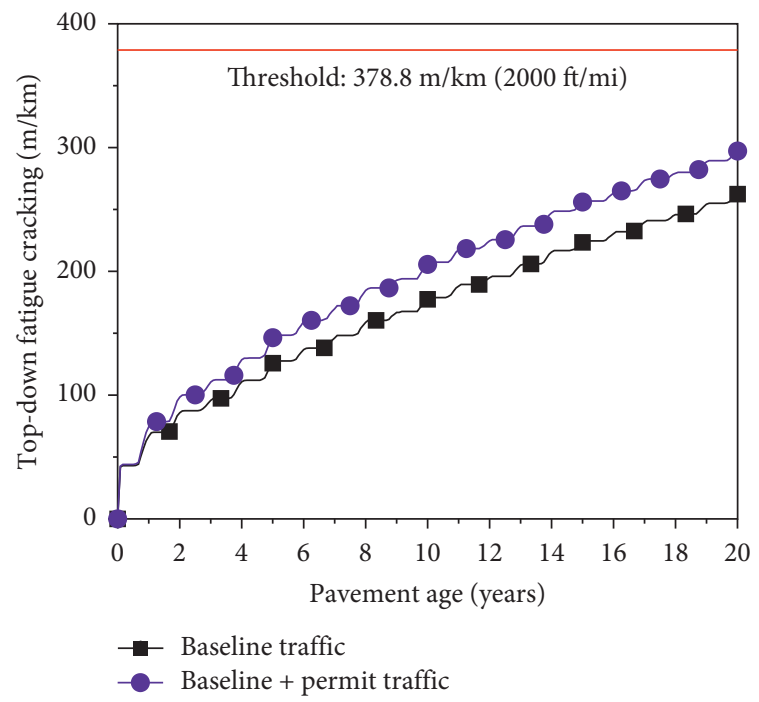

(d)

FIGURE 7: Detailed AASHTOWare Pavement ME distress predictions for STH 140 under baseline traffic loading versus baseline-plus-OWvehicles. (a) Predicted IRI, (b) predicted total permanent deformation, (c) predicted bottom-up cracking, and (d) predicted top-down cracking. 


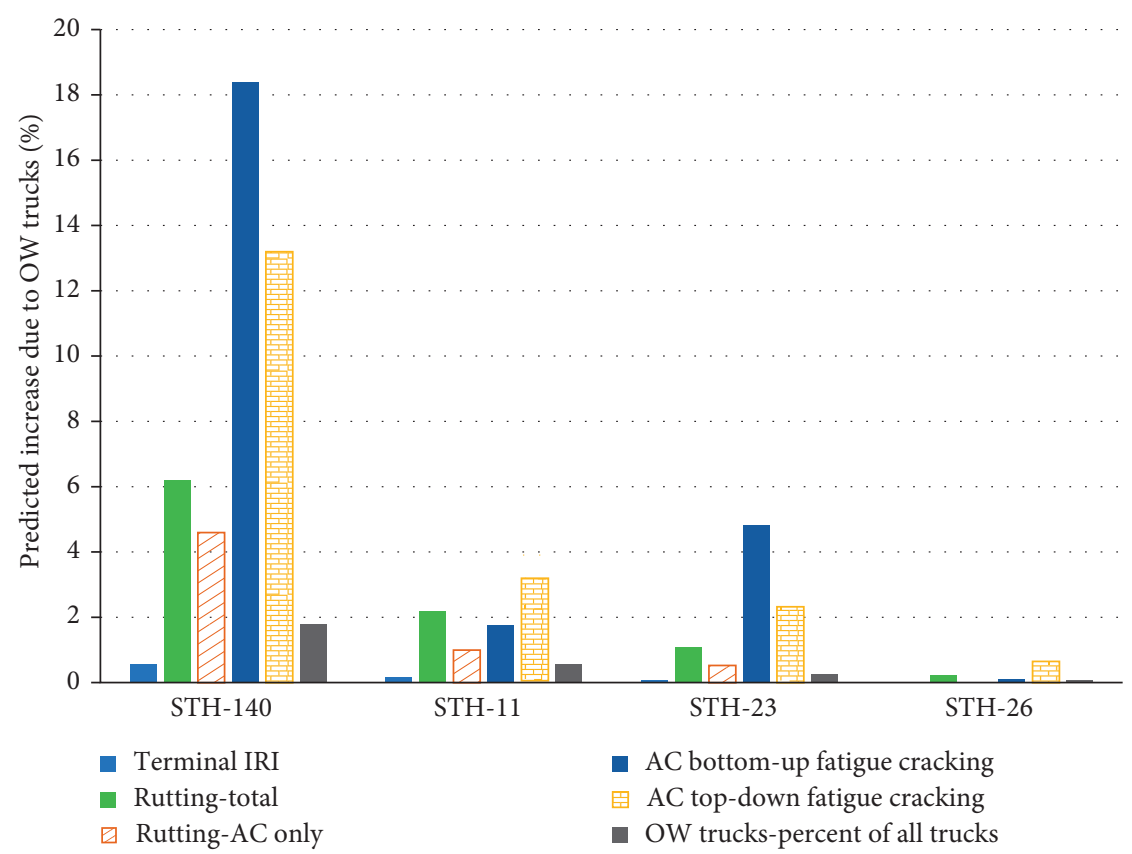

FIGURE 8: Relative increases in pavement distresses predicted by ME analyses due to the addition of OW vehicles to baseline traffic and relative proportion of OW trucks.

of STH 140, this analysis would likely lead to increasing the pavement thickness during the next rehabilitation or reconstructing the pavement with a pavement structure that is more resistant to high-traffic loadings than would normally be considered on a rural highway. The increased availability of OW permit data combined with the advanced analysis tools provided by ME methodologies enable comparative analyses of $\mathrm{OW}$ traffic scenarios as presented in this paper, which can significantly inform pavement design and rehabilitation processes.

\section{Data Availability}

The data used to support the findings of this study can be obtained from the OSOW Unit of WisDOT.

\section{Disclosure}

This work is based on an MS thesis by Valbon Latifi under the supervision of Hani $\mathrm{H}$. Titi; however, the research presented herein includes significant revisions, modifications, and updated data and results that were added between 2014 and 2017.

\section{Conflicts of Interest}

The authors declare that they have no conflicts of interest.

\section{Acknowledgments}

This work was supported in part by the Wisconsin Department of Transportation (WisDOT), through Project 0801-12-25, and by the National Center for Freight and Infrastructure Research and Education (CFIRE). The authors thank the staff of the Wisconsin DOT for their assistance in acquiring and interpreting permit data, especially Kathleen Nichols, Edward Lalor, and Laura Fenley. The authors also thank Dan Mulder and William Wondrachek of WisDOT for their partial financial support of the project.

\section{References}

[1] Federal Highway Administration (FHWA), Commercial Vehicle Size and Weight Program, FHWA: Freight Management and Operations, Atlanta, GA, USA, 2013, http://ops.fhwa.dot. gov/freight/sw/overview/index.htm.

[2] Wisconsin State Legislature, Wisconsin Statutes: VehiclesSize, Weight, and Load, Chapter 348, Wisconsin State Legislature, Wisconsin State Legislature, Madison, WI, USA, 2017.

[3] D. H. Chen, J. Bilyeu, and Z. Li, "Field evaluation of damages from super heavy load moves," in Proceedings of the GeoHunan International Conference, pp. 187-192, Kansas, MO, USA, May 2009.

[4] T. M. Adams, J. Bittner, and E. Wittwer, "Wisconsin Truck Size and Weight Study," Report CFIRE 02-0, National Center for Freight and Infrastructure Research and Education, University of Wisconsin-Madison, Madison, WI, USA, 2009.

[5] Wisconsin Department of Transportation, Oversize-Overweight Permits, 2018, http://wisconsindot.gov/Pages/dmv/com-drvvehs/mtr-car-trkr/osowgeneral.aspx.

[6] T. Adams, S. Malaikrisanachlee, C. Blazquez, and A. P. Vonderohe, "GIS-based oversize/overweight vehicle routing system," Report 0092-45-19, University of WisconsinMadison, Madison, WI, USA, 2002.

[7] F. J. Jooste and E. G. Fernando, "Victoria superheavy load move: report on route assessment and pavement modeling," Report FHWA/TX-94/1335-1, Texas A\&M University, Texas Transportation Institute, College Station, TX, USA, 1994. 
[8] J. H. Oh and A. J. Wimsatt, "Seal coat damage evaluation due to superheavy load moves based on a mechanistic-empirical approach," Report FHWA/TX-10/0-5270-1, Texas A\&M University, Texas Transportation Institute, College Station, TX, USA, 2010.

[9] D. H. Chen, J. Bilyeu, and J. R. Chang, "A review of the superheavy load permitting programme in Texas," International Journal of Pavement Engineering, vol. 6, no. 1, pp. 47-55, 2005.

[10] S. Owusu-Ababio and R. Schmitt, "Effects of heavy loading on Wisconsin's concrete pavements," Report WHRP 05-06, University of Wisconsin-Platteville, Department of Civil and Environmental Engineering, Platteville, WI, USA, 2005.

[11] X. Chen, J. R. Lambert, C. Tsai, and Z. Zhongjie, "Evaluation of superheavy load movement on flexible pavements," International Journal of Pavement Engineering, vol. 14, no. 5, pp. 440-448, 2013.

[12] B. Acimovic, L. Rejaseker, and R. Akhavan, "Forensic investigation of pavement failure on Vasquez boulevard," Report CDOT-2007-7, Colorado Department of Transportation, Denver, CO, USA, 2007.

[13] T. D. Gillespie, S. M. Karamihas, D. Cebon et al., "Effects of heavy vehicle characteristics on pavement response and performance," Report UMTRI 92-2, University of Michigan Transportation Research Institute, Ann Arbor, MI, USA, 1992.

[14] C. Tirado, C. Carrasco, J. M. Mares, N. Gharaibeh, S. Nazarian, and J. Bendana, "Process to estimate permit costs for movement of heavy trucks on flexible pavement," Transportation Research Record: Journal of the Transportation Research Board, vol. 2154, no. 1, pp. 187-196, 2010.

[15] J. H. Oh, E. G. Fernando, and R. L. Lytton, "Evaluation of damage potential for pavements due to overweight truck traffic," Journal of Transportation Engineering, vol. 133, no. 5, pp. 308-317, 2007.

[16] N. Coley, H. H. Titi, and V. Latifi, "Mapping overweight vehicle permits for pavement engineering applications," Journal of Transportation Engineering, vol. 142, no. 10, 2016.

[17] American Society for Testing and Materials (ASTM), Standard Practice for Roads and Parking Lots Pavement Condition Index Surveys, D6433-11, ASTM, West Conshohocken, PA, USA, 2011.

[18] H. H. Titi and R. English, "Determination of resilient modulus values for typical plastic soils in wisconsin," Report WHRP 11-04, Wisconsin Highway Research Program, Madison, WI, USA, 2011.

[19] Wisconsin Department of Transportation (WisDOT), 2007 Wisconsin Vehicle Classification Data, WisDOT, Madison, WI, USA, 2008. 


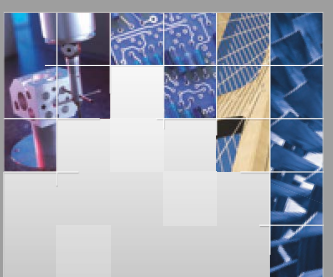

\section{Enfincering}
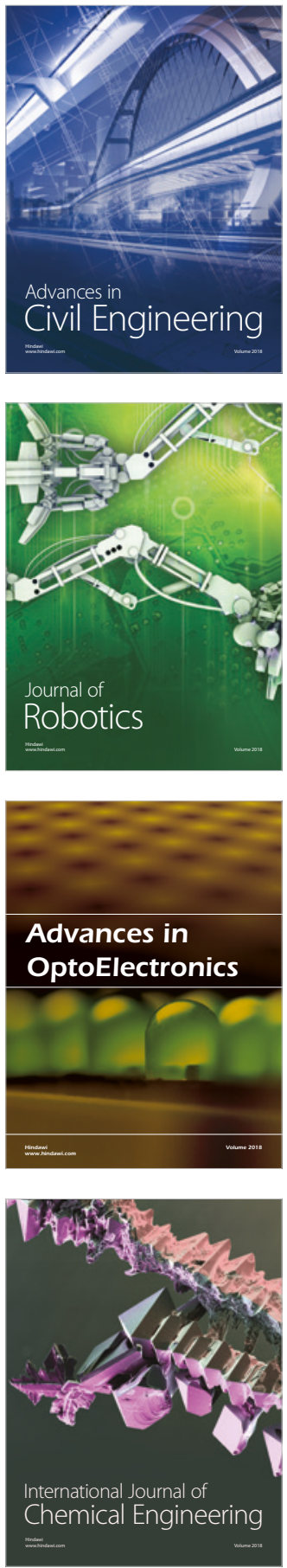

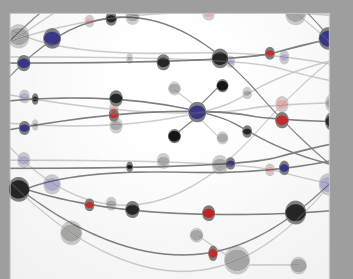

\section{Rotating \\ Machinery}

The Scientific World Journal

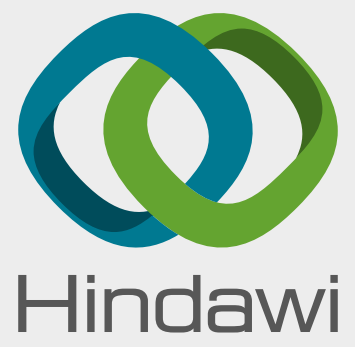

Submit your manuscripts at

www.hindawi.com
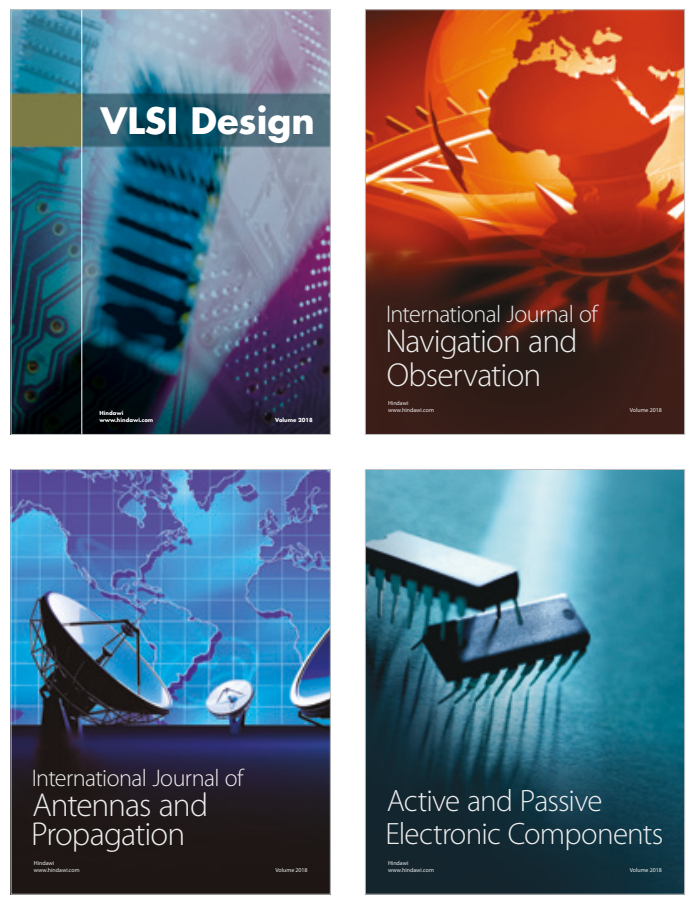
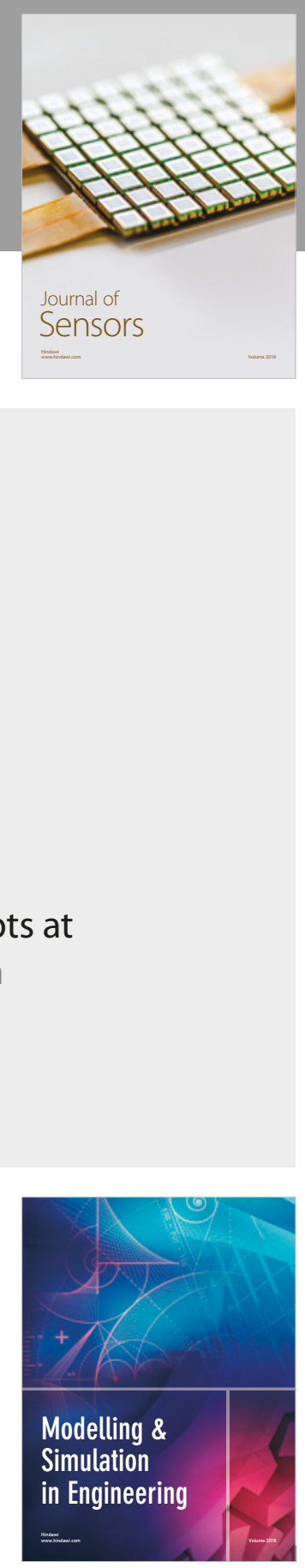

\section{Advances \\ Multimedia}
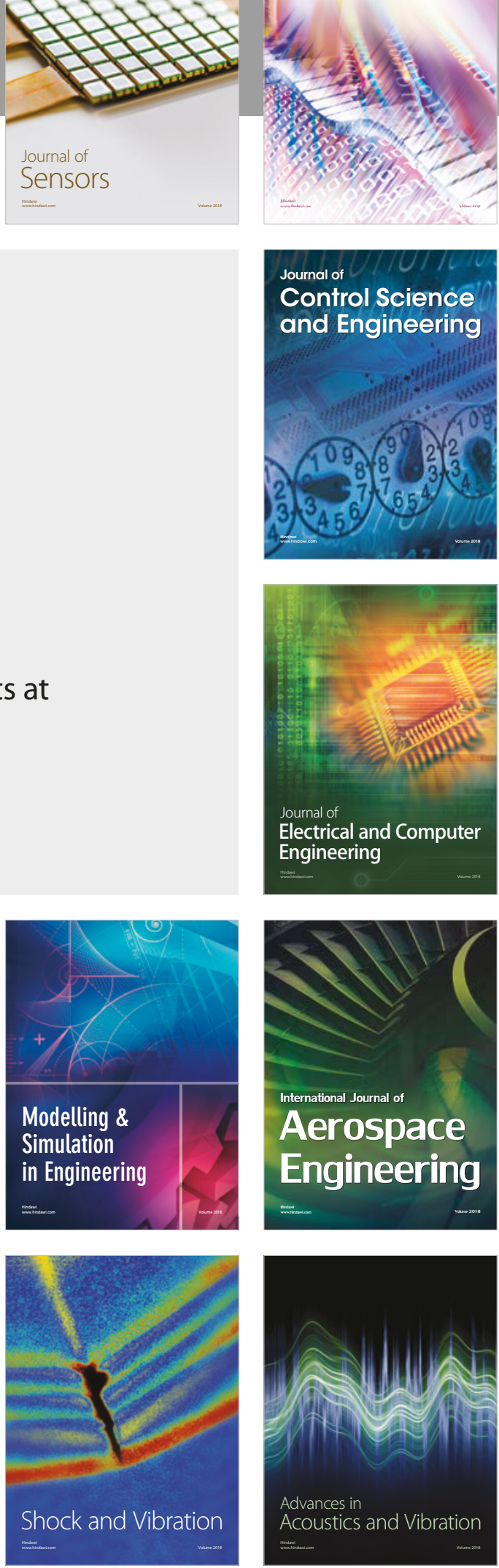